\title{
Informed consent: study of quality of information given to participants in a clinical trial
}

\author{
Niels Lynöe, Mikael Sandlund, Gisela Dahlqvist, Lars Jacobsson
}

\begin{abstract}
Objective-To determine whether the participants in a clinical trial had perceived adequate information about the trial according to the guidelines of the Declaration of Helsinki.

Design-About 18 months after the end of a gynaecological clinical trial the participants received a questionnaire by post, which focused on the quality of the information given to them before entering the trial. Neither researchers nor participants were aware in advance that the trial would become the subject of this follow up investigation.

Setting - Eight different centres in Sweden.

Subjects -43 women out of the 53 who completed the trial (mean (range) age 23 (16 to 35 ) years) returned the questionnaire.
\end{abstract}

Main outcome measures-Adequacy of the information (based on requirements of the Declaration of Helsinki) to enable the following: understanding of the aims of the study; awareness of what participation meant; and awareness of the possibility of withdrawing from participation at any time. Motives for agreeing to participate, and a subjective evaluation of the given information were also recorded.

Results - All but one of the participants had been aware that they were taking part in a research project. Five women stated that they had not been aware that a second laparoscopy was performed only for research reasons. Seven women reported that they had not been aware of the meaning of participating in the project and 17 that they had had no information about the possibility of withdrawing from the study whenever they wanted. In the subjective rating 22 women considered the information given as good or very good. There was a systematic variation in the quality of the given information among the eight centres.

Conclusion-Although all but one of the participants had been aware that they were taking part in a clinical trial, the quality of the information understood and recalled by participants varied, and in many cases clearly did not meet the guidelines of the Declaration of Helsinki. Variations among centres in participants' perception of information suggest that deficiencies in perception may be caused by informers rather than the participants.

\section{Introduction}

A central concept in modern clinical research ethics is informed consent, which is meant to guarantee the voluntary nature of participation in research studies. ${ }^{1}$ According to the Declaration of Helsinki, ${ }^{2}$ participants must receive adequate information concerning the project's aims, methods, expected benefits, and potential hazards and discomforts. Furthermore, experimental subjects must be informed that they can abstain from participation in the study and are free to withdraw their participation at any time, without any risk with regard to the quality of the ordinary treatment. Provided that the participant understands the importance of the information and is fully capable of making a decision, informed consent can be obtained. ${ }^{13}$
There are several studies on informed consent in connection with clinical research. These deal mainly with the legal aspect of participation, and how the information is perceived. ${ }^{45}$ Some discuss how to optimise the process of giving information and obtaining consent so that participants can recall the information. ${ }^{6-8} \mathrm{We}$ are aware of only one previous investigation - for a clinical trial of a drug for inducing delivery - on the information given to participants in which neither they nor the researchers knew in advance that the study would become the subject of a follow up investigation. ${ }^{9}$ The author found that 20 out of 51 women were unaware that they had taken part in a clinical experiment. We examined for a gynaecological research project the extent of information given to participants, how the information was given, and how the participants perceived the information.

\section{Patients and methods}

On the basis of our experience from a previous study on a research ethics committee in Sweden ${ }^{10}$ we chose a completed gynaecological trial" for this follow up investigation of quality of information given to the participants. The trial was methodologically well planned and was conducted by a qualified research leader; the protocol is outlined in the box. It was a multicentre study, which provided the opportunity for comparisons among centres. Furthermore, it was easy to distinguish the health care measures from the research measures. The disease was not harmful to life, and because all of the participants were less than 36 years old we could assume that they were competent at making decisions. All centres had participated in the design stage of the project, but at two centres the researchers involved at the design stage were not the same as those who had actually conducted the trial.

According to the protocol that was presented to the research ethics committee, the patients should have been informed orally and in writing when approached and when consent was sought. (In Sweden it is

\section{Outline of the protocol of the gynaecological study}

Apart from a description of the plan, purpose, and technical procedures of the gynaecological study the protocol contained information about the pros and cons for the participating patients and specified the following:

- That the patients should be informed orally and in writing when approached and when consent was sought

- That the patient should have written information before consent was sought

- That consent should not be sought on the same occasion as when information about the study was provided

- That it was not planned to seek written or signed consent, neither in connection with the diagnostic laparoscopy nor in connection with the scientifically motivated "second look" operation 
generally recommended that information should be given both orally and in writing, but it is under debate whether participants should sign a written consent.)

The aim of the gynaecological study was to investigate the effect of different drugs in women with acute inflammation of the fallopian tube (salpingitis acuta). The mean (range) age of the women at the time of the study was 23 (16-35) years. The patients were divided at random into a treatment group and a control group, and the study was double blind. The treatment group was given antiphlogistic drugs in addition to the usual antibiotics, while the control group received antibiotics and a placebo. The diagnosis was established by laparoscopy before treatment. Follow up entailed a second laparoscopy three to four months after the onset of the disease. This second laparoscopy ("second look operation") was performed for research purposes alone, whereas the initial laparoscopy was part of a routine diagnostic procedure.

During a two year interval 68 patients were recruited to the gynaecological study. Fifteen women did not have the second look operation for various reasonsfor example, pregnancy and moving house. These women were therefore excluded from the study and it was impossible for us to trace them. The study thus comprised 53 women who could be evaluated. We were able to trace the current addresses of 48 of them, and about 18 months after the end of the gynaecological study we posted a questionnaire to these 48 women who had been treated at eight different centres. The delay of 18 months was mainly caused by the time taken to develop the research plan and questionnaire, trace the participants, and get the approval of the concerned research ethics committees. The main questions were as follows: (1) When did you receive information? (2) Was the information oral, written, or both? (3) Did you receive the information at an appropriate time? (4) Did you know the aim of the project? (5) Did you know what your participation meant? (6) Did you know that you had the option to withdraw your participation at any time? (7) Did you weigh up the pros and cons of participating? (8) Did you know that the second look operation was an extraordinary measure? (9) Why did you choose to participate? (10) In general, how did you perceive the information given?

In view of the length of the time interval before questioning the alternative "can't recall" was included among the possible answers to each question. After two reminders 43 completed questionnaires were returned, representing eight different centres. The five participants who did not respond were distributed among four different clinics.

In view of the results we sent the researchers in the study a questionnaire with questions on the procedure used when informing the patients and seeking consent. We also asked them to estimate how many patients initially declined to participate. Finally, we contacted the research leader in order to clarify whether or not all of the researchers had been involved in the design stage of the study.

\section{Results}

All but one of the participants answered that they had received information about the study. Ten said that they had been informed when admitted to the hospital, 28 when the diagnosis was established, and one when she went for the second look operation. One subject stated that she had not been informed at all and three could not recall whether they had been informed or not. Thirty seven women thought that the information had been given at an appropriate time. Half of those who had been informed (21/42) had received oral information and the other half both written and oral
TABLE I-Knowledge of gynaecological trial and whether pros and cons of participation were considered in 42 participants according to type of information received

\begin{tabular}{|c|c|c|c|c|}
\hline Type of information ${ }^{\star}$ & Knew aim & $\begin{array}{l}\text { Knew of } \\
\text { possibility to } \\
\text { withdraw }\end{array}$ & $\begin{array}{c}\text { Knew } \\
\text { purpose of } \\
\text { second look } \\
\text { operation }\end{array}$ & $\begin{array}{l}\text { Considered } \\
\text { pros and } \\
\text { cons }\end{array}$ \\
\hline \multirow{2}{*}{$\begin{array}{l}\text { Oral }(n=21) \\
\text { Written and oral } \\
\quad(n=21)\end{array}$} & 18 & 8 & 17 & 7 \\
\hline & 19 & 11 & 20 & 11 \\
\hline
\end{tabular}

*One woman received no information.

TABLE II-Participants' answers to questions 4, 5, and 6 of questionnaire

\begin{tabular}{lcrc}
\hline & Yes & No & $\begin{array}{c}\text { Cannot } \\
\text { recall }\end{array}$ \\
\hline Did you know aim of study? & 37 & 4 & 2 \\
Did you know meaning of participating? & 34 & 7 & 2 \\
Did you know of possibility to withdraw? & 19 & 17 & 7 \\
\hline
\end{tabular}

information. Combining oral and written information tended to give a better quality of informed consent (table I).

Of the 43 participants, 35 answered that they had given consent; one said that she had not. This woman stated that she had never received any information and that she had been unaware of her participation in a research project until she received our questionnaire. Seven women stated that they did not remember whether or not they had given their consent.

Questions 4, 5, and 6 concern the quality of information and refer directly to the statements of the Declaration of Helsinki. Table II gives participants' answers to these questions.

An indication that informed consent had been secured was that the participants had been able to weigh up the pros and cons of their participation before consenting (question 7). Of the 43 respondents, 18 stated that they had done so and 24 that they had not. Several women commented that they had not found the time or that the situation had been far too stressful. Women who had weighed up the pros and cons before consenting were significantly older $(p<0.05)$ compared with those who had not. According to the researchers, consent had been sought on the same occasion as information was given.

Another indication of whether the patients had received adequate information concerning the research plan and the degree of risk associated with the second look operation was their understanding that the second look operation had not been a routine measure (question 8). Out of 43 respondents, four had perceived the second look operation as purely routine, and one stated that she had not known that its purpose was for research. One woman could not recall whether or not she had been informed of the purpose of the second look operation.

Motives for agreeing to participate-The researchers estimated that only a few patients had declined to participate in the study. Of the 43 respondents, 24 stated that their motive for agreeing to participate had been that the study might have benefits for future patients, 15 had seen the study as offering a chance to receive better care, and four women had agreed to

TABLE III - Participants' evaluation of information on clinical study according to reasons given for participating

\begin{tabular}{|c|c|c|c|c|c|}
\hline & $\begin{array}{l}\text { Very } \\
\text { good }\end{array}$ & Good & $\begin{array}{l}\text { Neither } \\
\text { good nor } \\
\text { bad }\end{array}$ & $\mathrm{Bad}$ & $\begin{array}{l}\text { Very } \\
\text { bad }\end{array}$ \\
\hline $\begin{array}{l}\text { Benefit of future patients } \\
(\mathbf{n}=24)\end{array}$ & 14 & 9 & 1 & & \\
\hline Other motives $(n=18)$ & 4 & 10 & 2 & & 2 \\
\hline
\end{tabular}

*One woman received no information. 
participate because their doctors had asked them to. Table III shows the participants' subjective evaluation of the information they received according to the most common reasons given for participating.

The participants' subjective evaluation of the information (question 10) indicated that they did not have to think the information "good" for it to be adequate. Guided by the Declaration of Helsinki, we divided the quality of the information into different levels. Table IV combines participants' responses to these levels with their subjective evaluation of the information. Agreement between our classification of perception of the information and the patients' subjective rating was apparent.

Comparison between different clinics-Five of the six women who stated that they had been unaware of the possibility to stop participating in the study had not been aware that the second look operation was a measure motivated by research, and one woman could not remember whether she had been aware of this. These six women comprised the participants from two clinics. None of these six had received written information. According to the research leader, all of the clinics had participated in the design stage of the research. However, in these two clinics, from which the patients perceived the information as bad or very bad, the procedures concerning information and laparoscopy had been delegated to two other researchers, who had not been involved in the planning stage of the project.

\section{Discussion}

\section{QUALITY OF INFORMATION}

All but one of the participants had been aware that they were taking part in a clinical trial. However, our study discloses several deficiencies in the information given to and understood by the participants. Thus at least 17 out of 43 women had not been aware that they could change their mind about participation, and, more seriously, five out of 43 had not been aware that the second look operation was performed purely for scientific reasons. According to the principles of the Declaration of Helsinki there is no ethically acceptable motive for limiting the amount of information in this kind of clinical study. One explanation for these deficiencies in information may be that the participants did not understand the information. A delay of 18 months before we interviewed the women might also have affected their ability to remember certain details. Studies have shown that the extent of perception of information about research studies depends on factors such as age, mental state, and type and seriousness of the disease, and also on participants' expectations. ${ }^{6-8}$ In our study the patients were young and mentally fully competent. The importance of an admission to hospital may have improved several of the women's ability to remember. By including "cannot recall" as a possible answer to each question any other answer indicates that the patients had some memory of their experience, and it would be difficult to explain the shortcomings of the perceived information as being due to bad recall alone.

TABLE IV-Participants' evaluation of information on study according to their response to levels of quality of information derived from questions guided by Declaration of Helsinki

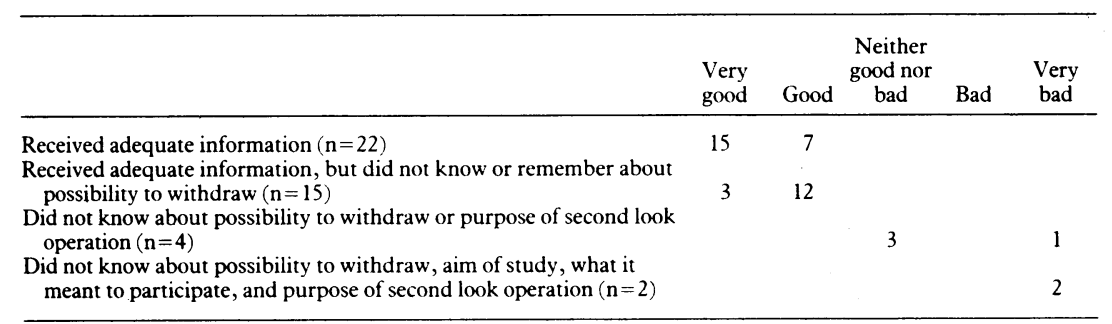

Furthermore, the presence of systematic differences among different centres indicates that it was the providers of the information rather than the receivers who were to blame for the low quality of perceived information. In fact, the researchers who had been responsible for distributing the information at the two clinics where the participants had been insufficiently informed had not taken part in the planning of the gynaecological study.

The quality of perceived information was increased when both written and oral information were given compared with that with oral information alone. There is at present a continuing debate in Sweden whether or not signed consent should be obtained. It cannot be claimed that signed consent may improve the chances of the participants remembering the information. Also, a signed consent procedure may make the participant feel bound to fulfil the participation, thereby reducing the voluntary nature of participation in research projects. The occasion at which the information is given seems to be an important factor. Too short a time to consider the pros and cons may make it difficult for the patient to decide freely about whether or not to participate.

\section{PATIENT MOTIVATION}

The majority of the women were motivated to participate by the consideration of benefiting future patients, and most of these participants perceived the information as very good. Thus a participant who is adequately informed seems to be more altruistic. The written information given to the patients did not indicate that the second look operation was of medical advantage to them. Nevertheless, 15 women were motivated in their decision to participate by the possibility of receiving better treatment. They might have perceived the second look operation as a special offer-a perception brought about by information given orally.

\section{ETHICAL PROBLEMS}

Three main ethical problems arose in connection with our questionnaire study. The first concerns the inconvenience caused to the participants; the second the unpleasantness caused to the researchers; and the third the problem of secrecy when the researchers agreed to cooperate with us, thereby making it possible to trace their former patients.

Acute inflammation of the fallopian tubes is recognised as a sexually transmitted disease. Despite the fact that the general attitude towards sexually transmitted diseases in Sweden today is probably much less prejudiced than before, some of the women might have feared being reminded of a situation they would rather relegate to the past. Friends or relatives might happen to see the questionnaire, thus exposing something the woman had chosen to keep a secret. None of the respondents, however, expressed any comments indicating that our investigation had any such undesirable effects, though some women commented that they received information through our questionnaire that they should have received much earlier.

An ethical problem of a more professional nature was caused by the fact that we chose to investigate the information provided to the participants in a project in which the researchers did not know in advance that such an investigation was going to be done. The researchers did, however, have the opportunity to decline by not helping in the collecting of names and addresses of the former experimental subjects. All of the researchers agreed to participate. To contact former participants who had been assured anonymity and had not been informed that the study was going to be the subject of a follow up investigation created a problem concerning secrecy. None of the respondents, 
however, made any negative comments on this issue; on the contrary, several women commented that they thought this kind of study important. Our investigation was considered and approved by all the concerned research ethics committees.

\section{CONCLUSIONS}

We conclude that most of the participants in this trial had been informed, but in many cases the information did not follow the guidelines of the Declaration of Helsinki. One third of the participants had not been aware that they had the option of withdrawing their participation at any time. There were systematic differences between the various participating clinics in that certain clinics were better at informing their patients than others. Our findings indicate that it is important that the researchers who are responsible for carrying out the project in practice also participate in the design stage of the project. Despite the narrow limits of our investigation certain deficiencies in the informing procedures were indicated, and, despite the ethical dilemmas, it points out the need for further follow up investigations.
1 Faden RR, Beauchamp TL. A history and theory of informed consent. New York: Oxford University Press, 1986

2 World Medical Association. Helsinki Declaration, 1975. In: Beauchamp TL, Walters LW, eds. Contemporary issues in bioethics. 2nd ed. Belmont, California: Wadsworth Publishing Company, 1982.

3 Appelbaum PS, Roth LH. Competency to consent to research. Arch Gen Psychiatry 1982;39:951-8.

4 Stanley B, Guido J, Stanley M, Shortell D. The elderly patient and informed consent. Empirical findings. ЭAMA 1984;252:1302-6.

5 Silva MC, Sorell JM. Enhancing comprehension of information for informed consent: a review of empirical research. IRB. Vol 10. New York: Hastings consent: a review of empiric

6 Simes RJ, Tattersall NHN, Coates AS, Raghavan D, Solomon HJ, Smartt H. Randomised comparison of procedures for obtaining informed consent in

7 Cassileth BR, Zupkis RB, Sutton-Smith K, March V. Informed consent - why are its goals imperfectly realized? N Engl f Med 1980;302:896-900.

8 Taub HA. Informed consent, memory, and age. Gerontologist 1980;20:686-90. 9 Gray BH. Human subjects in medical experimentation: a sociological study of the conduct and regulation of clinical research. New York: Wiley-Interscience, 1975

10 Lynöe N, Jacobsson L. Kvalitet eller integritet-En pilotstudie av en forskningsetisk kommitté. (Quality of research or autonomy of the participants - a pilot study of a research ethics committee.) Lakartidningen 1987;84:3246-8.

11 Weström L. Behandling av akut äggledarinflammation med enbart antibiotika, eller med antibiotika i kombination med anti-inflammatorisk drog. (Treatment of salpingitis acuta with antibiotics solely or in combination with an antiphlogistic drug.) Protocol for the research ethics committees, Diavienomber 201-86, University of Lund, 1986.

(Accepted 3 fune 1991)

\title{
Increased sensitivity of dopamine receptors and recurrence of affective psychosis after childbirth
}

Department of Psychiatry, Institute of Psychiatry, London SE5 8AF

A Wieck, MRCPSYCH, lecturer

R Kumar, FRCPSYCH, reader M N Marks, DPHIL, lecturer S A Checkley, FRCPSYCH, dean

\section{Department of}

Neuroscience, Institute of

Psychiatry, London

SE5 8AF

A D Hirst, BSC, research

worker

I C Campbell, DSC, reader

Correspondence to:

Dr Kumar.

BMF 1991;303:613-6

\author{
A Wieck, R Kumar, A D Hirst, M N Marks, I C Campbell, S A Checkley
}

\author{
Abstract \\ Objective-To test the hypothesis that affective \\ psychosis after childbirth is associated with an \\ altered sensitivity to dopaminergic stimulation.
}

Design-Prospective study of pregnant women at high risk of developing an affective psychosis after childbirth. Clinical assessments in pregnancy and after delivery were made by using a semistructured interview (schedule for affective disorders and schizophrenia) and psychiatric illnesses were categorised according to operational criteria (research diagnostic criteria).

Setting-Obstetric and psychiatric departments in and around Greater London.

Subjects -29 pregnant women with a history of bipolar or schizoaffective psychosis and 47 control pregnant women. Of these, 16 from each group participated in a growth hormone challenge test and the results for 15 women in each group were analysed.

Interventions-On the fourth day postpartum women participating in the hormone challenge test were given a subcutaneous injection of a small dose $(0.005 \mathrm{mg} / \mathrm{kg})$ of the dopamine agonist apomorphine.

Main outcome measures-Growth hormone secretion in response to apomorphine as an index of the functional state of hypothalamic dopamine receptors.

Results - Eight of the 15 women at risk of psychosis subsequently had a recurrence of illness (five bipolar, one schizomanic, and two major depressive illnesses); these women had significantly greater growth hormone responses to apomorphine than the seven at risk women who remained well and the 15 controls, and there were no significant differences between groups in average baseline growth hormone concentrations. The mean (SD) concentrations for women with recurrence, women at risk who remained well, and control women respectively were: average baseline concentrations 1.06 (1.14),
$1.44(1.39)$, and $0.90(1.34) \mathrm{mU} / \mathrm{l}$; peak increase in concentrations $13.68(12.95), 3.46(4.68)$, and 3.40 $(3.83) \mathrm{mU} / 1$ (between group difference $\mathrm{p}<0.05$ ); average increase in concentrations $6.74(7.01), 1.78$ (3.39), and $1.40(2.05) \mathrm{mU} / 1$ ( $\mathrm{p}<0.05)$.

Conclusions-The onset of affective psychosis after childbirth was associated with increased sensitivity of dopamine receptors in the hypothalamus and possibly elsewhere in the brain. Such changes may be triggered by the sharp fall in circulating oestrogen concentrations after delivery.

\section{Introduction}

Childbirth is a potent precipitator of severe mental illness: a woman is about 20 times more likely to require admission to hospital for a psychotic illness in the month after delivery than in any month in the previous two years. ' Women with a history of affective psychosis, related or unrelated to childbirth, are particularly vulnerable, and relapse rates of $50 \%$ have been reported. ${ }^{2}$ Prospective investigations of such women through pregnancy and the postpartum period therefore permit rigorous evaluation of putative aetiological mechanisms.

Of all the endocrine changes taking place after parturition, the sharp fall in circulating sex steroid hormone concentrations is perhaps most likely to contribute to the precipitation of psychosis in predisposed women. Unlike most other hormones steroids have easy access to the brain and concentrations of oestradiol and progesterone in plasma and cerebrospinal fluid are highly correlated. ${ }^{4}$ Recent research has shown that oestrogens modulate the function of monoaminergic and, in particular, dopaminergic neurotransmitter systems in the central nervous system. ${ }^{56}$ Abnormalities of dopaminergic neurotransmission have been implicated in both schizophrenic and manic depressive illness, and Cookson has proposed that puerperal psychosis is triggered by the 